\title{
Formas de financiación informal de los comerciantes informales en Colombia Casos: Cúcuta, Ibagué y Villavicencio.
}

\section{Forms of informal financing of informal traders in Colombia Cases: Cúcuta, Ibagué and Villavicencio.}

\section{Resumen.}

Este artículo tiene por objetivo analizar la incidencia de la financiación informal en los beneficios económicos de comerciantes informales, ubicados en las ciudades de Cúcuta, Villavicencio e Ibagué en el año 2017, para tal efecto se aplicaron de manera aleatoria 490 encuestas a vendedores informales en las tres ciudades, donde se encontró que muchas personas recurren a esta modalidad de créditos, solo para financiar actividades de capital trabajo y no para ampliar el tamaño de sus negocios, asumiendo altas tasas de interés y pagos diarios; además se demostró que esta forma de financiación no incidió positivamente en los beneficios de los comerciantes.

Para comprobar el objetivo de la investigación se efectuó un modelo econométrico de corte transversal, se seleccionaron solamente los vendedores informales de las ciudades mencionadas en el párrafo anterior que tenían alguna forma de financiación. La variable dependiente es el beneficio neto y como variables independientes se tomaron los créditos informales y la financiación del sistema bancario entre otras.

\section{Palabras clave}

Economía informal, crédito informal, comerciantes informales, Colombia, modelo econométrico transversal.

JEL: E26, G23, J23, C31

The objective of this article is to analyze the incidence of informal financing on the economic benefits of informal traders, located in Cúcuta, Villavicencio and Ibagué cities in 2017, for this purpose 490 surveys were randomly applied to informal vendors in the three cities, where it was found that many people resort to this type of loans, only to finance working capital activities and not to expand the size of their businesses, assuming high interest rates and daily payments; It was also shown that this form of financing did not have a positive effect on the profits of the merchants.

In order to verify the objective of the research, a cross-section econometric model was carried out; only the informal vendors of the cities mentioned in the previous paragraph who had some form of financing were selected. The dependent variable is net profit and as 
independent variables, informal loans and financing of the banking system among others were taken.

Key words: informal economy, informal credit, informal traders, Colombia, cross-sectional econometric model.

\section{Introducción}

La economía informal y sus formas de financiación ha sido uno de los temas centrales de investigación en las áreas de economía social y economía financiera, por cuanto muchas de las actividades económicas que se desarrollan en el país se hacen bajo la figura de la informalidad y han sido financiadas por créditos alternativos como los gota a gota, prestamos de familiares, casas de empeño, o amigos, dadas las facilidades bajo las cuales son otorgados, donde los prestamistas asumen el pago de altas tasas de interés y algunos riesgos.

Este artículo presenta a la comunidad académica y científica de las ciencias sociales y económicas, el resultado de la investigación sobre las formas de financiación de los comerciantes en Colombia. Para tal efecto se seleccionaron las ciudades de Cúcuta, Ibagué y Villavicencio con datos a diciembre 2017, la proporción de población ocupada da manera informal fue del $69.5 \%, 54.8 \%$ y $55.5 \%$ respectivamente según información estadística del DANE (DANE, 2017).

Cabe mencionar que la investigación que dio origen a este paper partió de la siguiente pregunta de investigación: ¿Cuál es la incidencia de los prestamos informales en los beneficios de los comerciantes informales ubicados en las ciudades de Cúcuta, Villavicencio durante el año 2017?, cuyo objetivo general fue evaluar la incidencia de los préstamos informales en los beneficios de los comerciantes informales en las tres ciudades mencionadas.

Es importante resaltar que el modelo econométrico que se presenta es novedoso y fue construido a partir a partir de los planteamientos teóricos de distintos autores, cuyos aspectos fundamentales son coherentes para dar respuesta a la pregunta de investigación planteada en este documento. Se tomaron los resultados de las encuestas efectuadas de manera aleatoria a 490 comerciantes de un total de 1119, ubicados en el centro de cada ciudad, y se desarrolló una modelo de corte transversal para determinar la incidencia de los créditos informales en los beneficios de los comerciantes informales, aplicando el método de mínimos cuadrados ponderados, donde la variable dependiente es el beneficio y como variables independientes las diferentes modalidades de créditos como los prestamos gota a gota, los gastos y los años de escolaridad entre otros, se espera encontrar un efecto significativo de los prestamos gota a gota en las ganancias de estas personas.

En el presente artículo se desarrollan las siguientes secciones: en la primera, se efectúa la caracterización de la informalidad en las ciudades objeto de investigación, en la siguiente 
sección se realiza una descripción del material y los métodos aplicados en la investigación; a continuación se encuentra el análisis del marco teórico y estado del arte, luego el análisis de los resultados y finalmente las conclusiones.

\section{Caracterización de las ciudades objeto de investigación.}

Las ciudades seleccionadas Cúcuta, Villavicencio e Ibagué se caracterizan por presentar las mayores tasas de desempleo y subempleo en el país durante 2017, por registrar altas tasas de población ocupada de manera informal frente a la ocupada formalmente, en empresas de hasta 5 trabajadores, y también por presentar las mayores tasas globales de participación (TGP) en el país. En el periodo de enero a diciembre del 2017, se destaca la ciudad de Cúcuta por registrar la mayor tasa de desempleo (15.9\%) y la mayor proporción de población ocupada de manera informal (69.5\%) (DANE, 2017).

Tabla No 1: Indicadores de mercado laboral por ciudad de enero-diciembre 2017

\begin{tabular}{|l|r|r|r|r|r|r|r|}
\hline & \multicolumn{1}{|c|}{ TGP } & \multicolumn{1}{c|}{ TO } & \multicolumn{1}{c|}{ TS (Sus) } & TS & \multicolumn{1}{c|}{$\begin{array}{c}\text { Variación } \\
\text { (Objetiva) }\end{array}$} & $\begin{array}{c}\text { Proporción de } \\
\text { informalidad }\end{array}$ \\
\hline Quibdó & 57.1 & 47.9 & 19.7 & 5.8 & 16.1 & - & 56.4 \\
\hline Cúcuta & 62.7 & 52.8 & 25.8 & 13.8 & 15.9 & + & 69.5 \\
\hline Ibagué & 65.4 & 56.9 & 27.5 & 10.9 & 12.9 & - & 54.8 \\
\hline Armenia & 64.5 & 55.3 & 29.1 & 29.1 & 14.3 & - & 56.7 \\
\hline Riohacha & 63.8 & 54.8 & 32.3 & 16.6 & 14.0 & + & 64.5 \\
\hline Cali & 68.1 & 60.1 & 29.7 & 11.3 & 11.9 & + & 54.1 \\
\hline Villavicencio & 66.8 & 58.6 & 18.0 & 8.5 & 12.3 & + & 55.5 \\
\hline Bogotá D.C. & 69.6 & 62.3 & 22.4 & 8.4 & 10.5 & + & 41.7 \\
\hline
\end{tabular}

Fuente: Departamento Nacional de Estadística DANE (DANE, 2018).

Es de resaltar que Cúcuta es una ciudad ubicada en el nororiente colombiano y su economía se basa en el comercio transfronterizo con Venezuela, la actividad comercial entre los dos países repercute en la tasa de cambio, por lo cual el diferencial de precios en productos como la gasolina, alimentos y otras mercancías ha estimulado el fenómeno del contrabando, dada la rentabilidad de la actividad ilícita incidiendo en la estabilidad económica y social de esta ciudad.

Ibagué es una ciudad ubicada en el centro occidente del país, es un importante eje financiero y económico de Colombia. Basa su economía en el sector industrial, teniendo varias de las empresas más reconocidas de Colombia. En cuanto al sector primario, se desarrollan las actividades de ganadería, agricultura y la minería. Además se destacan los cultivos de arroz, algodón y a la vez es un gran productor y exportador de café. De igual manera Ibagué tiene gran relevancia en cuanto a la industria textil, siendo esta la tercera ciudad textilera del país. 
La tercera ciudad seleccionada es Villavicencio, ubicada al sur de la ciudad de Bogotá, es la capital del departamento del Meta, su economía se centra en la extracción de petróleo y gas, aunque su principal fuente de empleo es la actividad de comercio y servicios.

\section{Material y métodos}

Para el desarrollo de los aspectos metodológicos, se efectuaron las siguientes fases para el cumplimiento del objetivo general, en la fase uno se diseñó una encuesta dirigida a los comerciantes informales ubicados en las ciudades de Cúcuta, Ibagué y Villavicencio.

En la fase dos, se efectuó un proceso de observación para determinar un número aproximado de vendedores informales ubicados especialmente en el centro de cada ciudad, pues es el sitio estratégico que permite obtener mejores resultados en ventas, luego se aplicó un instrumento diseñado para capturar la información de los comerciantes informales seleccionados aleatoriamente en cada ciudad. En las ciudades de Cúcuta e Ibagué se aplicaron 170 encuestas en cada una, en Villavicencio 150, que totalizan 490 sobre un total de 1119, que representa el $43,78 \%$.

En la fase tres se construyó un modelo econométrico de corte transversal donde se escogieron aquellos comerciantes informales que tenían alguna forma de financiación tanto formal como informal. En total se seleccionaron para la construcción del modelo 150 comerciantes informales, de las tres ciudades. Posteriormente se diseñó un modelo novedoso de mínimos cuadrados ponderados, alternativo de estimación de parámetros en un modelo lineal generalizado. Este método fue desarrollado por Grizzle, Starmer, Koche (1969).

Un modelo lineal generalizado expresa de manera cuantitativa una serie de relaciones entre un conjunto de variables, siendo una de ellas la variable dependiente y las demás las variables independientes o explicativas y se definió la siguiente ecuación:

$\log ($ Beneficio $)=\beta_{0}+\beta_{1}$ credito_siste $+\beta_{2}$ conoce_requisitos $+\beta_{3}$ fincia_recursos_pr opios $+\beta_{4}$ Escolaridad $+\beta_{5}$ Vivienda_propia $+\beta_{6} T E A+\beta_{7}$ competencia $+\beta_{8}$ dependientes $+\beta_{9}$ credito_informal $+\beta_{10}$ frecuencia_surtido $+\varepsilon$

\subsection{Identificación de variables}


Para la construcción modelo se seleccionaron las siguientes variables, a partir de la encuesta aplicada se evidencio que tenían una incidencia significativa sobre los beneficios netos de los comerciantes informales de las ciudades objeto de estudio. Estas variables se pueden observar en la tabla No. 2.

Tabla No 2 identificación de variables

\begin{tabular}{|c|c|c|}
\hline Variable & Descripción & $\begin{array}{l}\text { Resultado } \\
\text { esperado }\end{array}$ \\
\hline $\begin{array}{l}\log (\text { Beneficio }) \\
\text { Variable dependiente }\end{array}$ & $\begin{array}{l}\text { Beneficio neto definido como la } \\
\text { diferencia entre ingresos y gastos } \\
\text { obtenidos durante la semana anterior. }\end{array}$ & \\
\hline $\begin{array}{l}\text { credito_siste } \\
\text { Independiente }\end{array}$ & $\begin{array}{l}\text { Gestiono crédito con el sistema } \\
\text { financiero durante el último año. }\end{array}$ & Positivo \\
\hline $\begin{array}{l}\text { conoce requisitos } \\
\text { variable Independiente }\end{array}$ & $\begin{array}{l}\text { Conoce los requisitos para acceder al } \\
\text { sistema financiero }\end{array}$ & Positivo \\
\hline $\begin{array}{l}\text { fincia_recursos_propios } \\
\text { variable Independiente }\end{array}$ & $\begin{array}{l}\text { Opciones si financia con recursos } \\
\text { propios y no }\end{array}$ & Positivo \\
\hline $\begin{array}{l}\text { Escolaridad } \\
\text { Variable Independiente }\end{array}$ & Años de escolaridad & Positivo \\
\hline $\begin{array}{l}\text { Vivienda propia } \\
\text { Variable Independiente }\end{array}$ & Tenencia de vivienda propia & Positivo \\
\hline $\begin{array}{l}\text { Competencia } \\
\text { Variable Independiente }\end{array}$ & $\begin{array}{l}\text { Competidores de su actividad estima } \\
\text { que hay en un radio de dos cuadras }\end{array}$ & Positivo \\
\hline $\begin{array}{c}\text { dependientes } \\
\text { Variable independiente }\end{array}$ & $\begin{array}{llll}\text { Cuantas } & \text { personas } & \text { dependen } & \text { del } \\
\text { negocio incluido el dueño } & \text { del } \\
\text { negocio. } & & & \\
\end{array}$ & Negativo \\
\hline $\begin{array}{l}\text { crédito informal } \\
\text { variable independiente }\end{array}$ & $\begin{array}{l}\text { Créditos con prestamistas informales } \\
\text { para financiar la actividad. }\end{array}$ & Negativo \\
\hline $\begin{array}{l}\text { frecuencia surtido } \\
\text { Variable independiente }\end{array}$ & $\begin{array}{l}\text { Frecuencia para surtir el negocio en } \\
\text { número de días. }\end{array}$ & Positivo \\
\hline
\end{tabular}

Fuente: Elaboración propia a partir del instrumento aplicado a comerciantes informales de las ciudades de Cúcuta, Villavicencio e Ibagué, 2017.

\section{$4 \quad$ Aspectos teóricos}

La financiación se constituye en una actividad importante para el desarrollo de la inversión y por lo tanto para el crecimiento de la demanda agregada y el crecimiento de la producción de un país o de una región. 
Keynes a través de la Teoría general de la Ocupación el interés y el dinero, considera que el ahorro tiene una estrecha relación con la demanda de inversión de las empresas y lo argumenta de la siguiente manera: "la equivalencia entre la cantidad de ahorro y la de inversión surge del carácter bilateral de las operaciones entre el productor, por una parte, y el consumidor o comprador de equipo de capital por la otra" (Keynes, 2003). Si el mercado es de competencia perfecta los agentes económicos empresariales pueden desarrollar sus actividades sin ninguna dificultad, porque el mercado se encarga de asignar los recursos productivos cuando el agente empresarial no dispone de los recursos suficientes para su inversión, asumiendo una tasa de interés de mercado para financiar las actividades productivas, para lo cual realiza una sustitución intertemporal entre el consumo presente para asumir la obligación crediticia que garantiza el equilibrio entre el ahorro y la inversión. (Romer, 2005) .

Por ello el ahorro se convierte en el principal vehículo de financiación para el desarrollo de la inversión lo que a su vez permite que la demanda y la oferta se mantengan en situaciones de equilibrio en el mercado y se permita alcanzar un nivel de bienestar. Por tanto la oferta de créditos es compensada con la demanda dado que los agentes tienen un comportamiento racional y el mercado facilita la asignación de recursos productivos, hasta garantizar diferentes situaciones de equilibrio.

Cuando los mercados fallan y los agentes no se comportan de manera racional, entonces, el equilibrio entre los fondos prestables y la inversión no se mantiene y por lo tanto los recursos no son asignados de manera equitativa para todos los participantes del mercado, porque se presenta una diferenciación en los tipos de empresas, por tanto el racionamiento de los créditos por parte de las entidades financieras, genera exclusión especialmente para aquellos agentes que no cuentan con suficientes garantías y recursos para cubrir la obligación.

Entre las características más importantes de los mercados de créditos imperfectos se destacan: los problemas de asimetrías de información entre agentes económicos, selección adversa, riesgo moral especialmente cuando se cobran tasas de interés elevadas y racionamiento. Por lo tanto la selección adversa y el riesgo moral aumentan la probabilidad de incumplimiento de los créditos lo que puede ocasionar el racionamiento en el otorgamiento de estos recursos por parte de la banca formal. (Robinson, 2001).

Sin embargo también se encuentran otras causas que limitan el acceso a los financieros formalizados como son una adecuada información, los elevados costos financieros, el tipo de garantías exigidas, disponibilidad de recursos propios. Estas imperfecciones en el mercado crediticio es lo que ha justificado la presencia de créditos alternativos y microcréditos para la financiación de empresas informales. Por lo tanto hay desajuste por el lado de la oferta y la demanda. Desde el punto de vista de la oferta, las entidades bancarias son restrictivas a la hora de otorgar préstamos a sectores que no tienen garantías ni ingresos suficientes para acceder a los créditos, por el lado de la demanda, la falta de información y confianza hacia 
la banca formal sumado a las exigencias entre otras demostrar certificado de ingresos otorgado por empresas formales y el tiempo de respuesta de las entidades bancarias hace que los solicitantes limiten sus solicitudes a las entidades financieras formales, recurriendo a fuentes de financiación más inmediatas aunque los intereses por los prestamos sean más elevados no son regulados por la Superintendencia financiera lo cual los hacen más riesgosos.

Diferentes estudios muestran que los créditos informales tienen unas características que son diferentes a los créditos formales. Kristiano Racanello (2013) considera que el mercado financiero formal surge como respuesta a la cantidad que exigencias que piden el sistema financiero formal principalmente en cuanto a garantías, inmediatez en la entrega de recursos, plazos a pesar de las tasas de interés y montos más bajos respecto a los créditos formales.

Identifica como créditos informales los siguientes: los otorgados por familiares y amigos allegados al hogar con alto nivel de confianza para poder negociar el pago de los intereses dada la reciprocidad, que se puede generar en este círculo de amigos donde se establecen relaciones entre individuos principalmente y los arreglos para pactar las condiciones de los préstamos, son informales aunque el incumplimiento de este tipo de compromisos genera drásticas sanciones no solo a quien incumplió con la obligación sino también a los mismo familiares. La amistad es otra categoría que también permite el otorgamiento de préstamos y se presenta cuando los familiares del prestatario no tienen recursos para otorgar los préstamos.

Otro tipo de préstamos informales son los efectuados a través de las cadenas, mediante los cuales varias personas familiares o no, se reúnen para efectuar depósitos mensuales de manera puntual y de manera aleatoria, se asigna una determinada cantidad de recursos acumulados de dinero a través de un proceso de subasta, una vez el integrante recibe una cantidad, no es elegible hasta que los otros miembros la han elegido. "Los agiotistas también se constituyen en otra figura característica de los créditos informales, cuando un individuo presta dinero a elevadas tasas de interés y tiene el respaldo de alguna garantía principalmente bienes muebles e inmuebles, sin embargo la reputación es un problema que generan este tipo de obligaciones pues mucha gente es consciente de los efectos que generan este tipo de solicitudes y el nivel de reproche que pueden ocasionar por la vergüenza que estos generan frente a familiares y amigos" (Racanello, 2013).

Se considera que los agiotistas son una manera de otorgar recursos por parte de bandas criminales o mafias, donde el objetivo no es cobrar intereses sino tomar posesión del patrimonio de los prestamistas para lavar dineros de otros negocios ilícitos, pero el no pago de estas obligaciones genera riesgos elevados que pueden ocasionar represalias a los usuarios de los créditos (Racanello, 2013, pág. 24).

Finalmente las casas de empeño también se convierten en otras de las figuras tradicionales de los créditos alternativos, se considera que los objetos que se empeñan son la joyería, 
relojes, anillos y hasta ropa. Se considera que el otorgamiento de estos créditos se otorga rápido y a corto plazo y cuando se vence el periodo del préstamo puede renovar el préstamo pagando los intereses al refrendar la prenda.

La mayoría de los agentes financieros informales tienden a especializarse en cualquiera de los tipos de préstamos antes mencionados donde la figura de membrecía es fundamental. Muchos investigadores estiman que el sector financiero informal es más grande que el sector financiero formal en términos de alcance, ya que estos préstamos son accesibles a la mayoría de los grupos socioeconómicos. También es estima que hay una demanda rápida y creciente para créditos informales dado el gran número de personas que se ubican en el sector informal que incluyen los créditos rurales. En diversos grados, los servicios financieros informales se caracterizan por facilitar el acceso, la flexibilidad el uso del préstamo, el rápido procesamiento y la entrega de recursos, la flexibilidad en las tasas de interés y requisitos de garantía (Aryeetey, 2008).

Se considera que los créditos informales tienen gran participación en los mercados informales y los prestamistas generalmente no son competitivos, la población pobre, algunos empresarios informales y las personas del sector rural, son los que más acuden a esta financiación. Las microfinanzas aparecen como un mecanismo de financiación que de alguna manera pueden resolver de forma más eficiente las falencias de esta forma de préstamo.

\subsection{Breve estado del arte.}

En el año 2014 la Cámara de Comercio de Cúcuta elaboro una encuesta de informalidad a 295 empresarios de la ciudad, destacando que la informalidad de la ciudad y el Área metropolitana era de 69\%, aprovechando las ventajas de la frontera para desarrollar principalmente actividades de tipo comercial. Destaca que el 60\% de estos empresarios, utiliza los préstamos de gota a gota seguidos por los préstamos de Bancamía y la Fundación de la Mujer (Cámara de Comercio de Cúcuta, 2016).

Otro estudio analiza el problema de la financiación informal y su relación con la actividad empresarial para las ciudades objetos de investigación. En el año 2015 Javier Rodríguez elaboró un trabajo de grado denominado: "Impacto financiero causado por los cuentagotas en microempresarios de Villavicencio", donde analiza las principales causas por las cuales los empresarios dedicados a la actividad comercial recurren a la financiación informal y sienten temor a la banca formal, por las restricciones que impone cuando estudian las solicitudes crediticias y el temor a los reportes de data crédito, utilizando principalmente la figura del gota a gota y concluye además que la edad no es un factor determinante para tomar esta decisión (Rodriguez \& Obando, 2015).

En África se han elaborado algunos estudios que abordan el comportamiento del sector financiero informal, destacándose los trabajos pioneros de Aryeetey (1994) para Ghana, 
Soyibo (1996) para Nigeria, Chipeta y Mkandawire (1996) para Malawi, y Bagachwa (1994) para Tanzania. Esos estudios documentan el crecimiento sustancial en las actividades del sector financiero informal, incluso en medio de las reformas del sector financiero. Su principal conclusión fue que a pesar de que el sector informal estaba creciendo, las unidades individuales eran dispuestas a aumentar el crédito de manera significativa, y esto fue en gran parte debido a la limitada o de manera poco ortodoxa en la que se abordan las cuestiones de riesgo moral y adversa selección. Como se sugirió anteriormente, por sus opciones operativas que hacen que sus productos no necesariamente atractivo para la mayoría de las pequeñas empresas en crecimiento (Aryeetey, 2008).

Una gran parte del crecimiento inicial que se observó en el sector informal a mediados de la década de 1990 es continuando en muchos países. En Ghana, por ejemplo, ahora es común encontrar que gran oficinas número de colectores su individuales han establecidos (kioscos) en varios puntos en las ciudades y pueblos donde sus clientes puede caminar para hacer depósitos y participar en otras transacciones. Así que claramente algún proceso de transformación se lleva a cabo en el negocio de la recolección de in hacer necesariamente formal en el sentido de regulación.

El número creciente de operadores informales sugieren que todavía hay una demanda significativa de sus servicios y esto explicaría por qué formales las instituciones financieras están empezando a dirigir alguna atención a la vinculación con ellos de una número de países (Aryeetey, 2008).

\section{Análisis de resultados y discusión}

\subsection{Caracterización de los comerciantes informales en las ciudades de Villavicencio, Cúcuta, e Ibagué a partir de los resultados obtenidos en las fases 1 y 2}

En las tres ciudades se encuestaron un total de 490 vendedores ambulantes; predominando la población masculina con el 52,67\%., con un promedio de escolaridad de 6,6 años para las tres ciudades. El 68,93\% cuenta con sistema de salud subsidiado, $19.17 \%$ tienen un régimen contributivo y el $11.9 \%$ no tiene ningún sistema de seguridad social. Finalmente el $33.91 \%$ de los vendedores ambulantes en promedio para las tres ciudades tiene vivienda propia y el resto vive en alquiler.

Tabla No 3 Aspectos generales de la encuesta aplicada a 490 comerciantes informales en las ciudades de Villavicencio, Cúcuta e Ibagué-Colombia

$\begin{array}{cccc}\text { Villavicencio } & \text { Cúcuta } & \text { Ibagué } & \begin{array}{c}\text { Total y } \\ \text { promedio }\end{array}\end{array}$




\begin{tabular}{|c|c|c|c|c|c|}
\hline \multicolumn{2}{|l|}{$\begin{array}{c}\text { Total } \\
\text { vendedores }\end{array}$} & 216 & 506 & 387 & 1119 \\
\hline \multicolumn{2}{|l|}{ Muestra } & 150 & 170 & 170 & 490 \\
\hline \multicolumn{2}{|l|}{$\begin{array}{c}\text { Porcentaje } \\
\text { participación }\end{array}$} & $69.44 \%$ & $33.60 \%$ & $43.93 \%$ & $43,78 \%$ \\
\hline \multirow[t]{2}{*}{ Género } & Femenino & $52,67 \%$ & $47,1 \%$ & $42,4 \%$ & $47.39 \%$ \\
\hline & Masculino & $47,33 \%$ & $52,9 \%$ & $57,6 \%$ & $52.61 \%$ \\
\hline \multicolumn{2}{|c|}{ Años medio de escolaridad } & 6 & 8 & 6 & 6,67 \\
\hline \multicolumn{2}{|c|}{ Años de escolaridad de la mayoría } & 5 & 11 & 5 & 7 \\
\hline \multirow{3}{*}{$\begin{array}{l}\text { Servicio de } \\
\text { salud }\end{array}$} & Subsidiado & $75 \%$ & $69,4 \%$ & $62,4 \%$ & $68,93 \%$ \\
\hline & Contributivo & $14 \%$ & $19,4 \%$ & $24,1 \%$ & $19,17 \%$ \\
\hline & Ninguno & $11 \%$ & $11.2 \%$ & $13,5 \%$ & $11,90 \%$ \\
\hline \multirow{2}{*}{$\begin{array}{c}\text { Tenencia de } \\
\text { vivienda }\end{array}$} & Alquiler & $70,76 \%$ & $58,2 \%$ & $69,4 \%$ & $66,12 \%$ \\
\hline & Propia & $29,33 \%$ & $41,8 \%$ & $30,6 \%$ & $33,91 \%$ \\
\hline
\end{tabular}

Fuente: Elaboración propia a partir de los datos tomados de la encuesta aplicada a los comerciantes informales en las ciudades de Cúcuta, Ibagué y Villavicencio, julio de 2017

\subsubsection{Caracterización de la muestra Villavicencio}

En el centro de esta ciudad se efectuó un proceso de observación y se encontró un total de 216 comerciantes informales, destacándose los puestos de venta de comidas $(67,11 \%)$ y en menor proporción las ventas de ropa $(7,40 \%)$, accesorios $(5,09 \%)$, libros $(3,24 \%)$ y otros $(17,12 \%)$.

La encuesta realizada de forma directa a las personas le fue aplicada a 150 empresarios, de los cuales el 52,67\% corresponden a mujeres y el $47,33 \%$ a hombres, la mayoría de estas personas se encuentran vinculados a un sistema subsidiado de salud (75\%), mientras que un $14 \%$ corresponden al contributivo y un $11 \%$ no tienen ninguna de estas dos categorías.

Con relación al nivel educativo el promedio aritmético de años de escolaridad es 6 años y medio aproximadamente, mientas que la mayoría dice haber estudiado 5 años y del $25 \%$ que más han estudiado lo mínimo para estos son 10 años escolares.

Respecto a la tenencia de vivienda el 70,76\% dice vivir en alquiler y el 29,33\% tiene vivienda propia, por último la distribución respecto al estrato socioeconómico se encontró que la mayoría pertenece al estrato 1 , seguidos del estrato 2 . 


\subsubsection{Caracterización de la muestra Cúcuta}

Como resultado del proceso de observación se encontraron 506 comerciantes informales localizados en el centro de la ciudad, donde se destaca como actividades comerciales las ventas de accesorios con el 32,21\% y la venta de alimentos (comidas rápidas, frutas). En su mayoría los trabajadores de estos negocios son sus propios dueños de sus y solo en pocos casos poseen ayudantes.

Tabla 4. Resultados fase de observación ciudad de Cúcuta.

\begin{tabular}{|c|c|c|}
\hline \multicolumn{2}{|c|}{ Resultados fase de observación } \\
\hline $\begin{array}{c}\text { Actividad Realizada por los } \\
\text { Trabajadores Informales de } \\
\text { Cúcuta }\end{array}$ & $\begin{array}{c}\text { Cantidad Total de Empresas } \\
\text { Informales }\end{array}$ & $\begin{array}{c}\text { Porcentaje de Participación de } \\
\text { las Empresas Informales según } \\
\text { su Actividad }\end{array}$ \\
\hline Venta de Accesorios & 163 & $32.21 \%$ \\
\hline Venta de Alimentos & 153 & $30.24 \%$ \\
\hline Venta de Ropa & 62 & $12.25 \%$ \\
\hline Venta de Otros & 57 & $11.26 \%$ \\
\hline Venta de Calzado & 36 & $7.11 \%$ \\
\hline Venta de Juguetería & 26 & $5.14 \%$ \\
\hline Venta de Libros & 9 & $1.78 \%$ \\
\hline TOTAL & 506 & $100.00 \%$ \\
\hline
\end{tabular}

Fuente: Elaboración propia a partir de los datos tomados de la encuesta aplicada a los comerciantes informales en las ciudades de Cúcuta, Ibagué y Villavicencio, julio de 2017

La encuesta realizada de forma directa a las personas le fue aplicada a 170 comerciantes informales de un total de 506 observados en el centro de la ciudad. Esta muestra representa el 33,6\% del total de comerciantes informales, de los cuales el 47,1\% corresponden a mujeres y el 52,9\% a hombres, la mayoría de estas personas se encuentran vinculados a un sistema subsidiado de salud $(69,4 \%)$, mientras que un $19,4 \%$ corresponden al contributivo y un $11,2 \%$ no tienen ninguna de estas dos figuras.

Con relación al nivel educativo para esta ciudad el promedio aritmético de años de escolaridad es un poco más de 8 años aproximadamente, mientas que la mayoría dice haber estudiado 11 años.

Respecto a la tenencia de vivienda el 58,2\% dice vivir en alquiler y el 41,8\% tiene vivienda propia, por último la distribución respecto al estrato socioeconómico se encontró que la mayoría pertenece al estrato 1, 90 encuestados; seguidos del estrato 2 con 56 encuestados.

\subsubsection{Caracterización de la muestra Ibagué.}


En esta ciudad se observaron 387 vendedores localizados en el centro de la ciudad y la actividad comercial que más se destaco fue la venta de alimentos con un $32 \%$ seguida de la venta de prendas de vestir y luego la venta de accesorios como bolsos cinturones billeteras.

Tabla 5. Resultados fase de observación ciudad de Ibagué.

\begin{tabular}{|l|r|r|}
\hline Actividad & $\begin{array}{l}\text { Cantidad } \\
\text { Vendedores }\end{array}$ & \multicolumn{1}{c|}{$\%$} \\
\hline Alimentos & 126 & $32,56 \%$ \\
\hline Accesorios & 95 & $24,55 \%$ \\
\hline Entretenimiento & 47 & $12,14 \%$ \\
\hline Prendas de vestir & 96 & $24,81 \%$ \\
\hline Otros & 23 & $5,94 \%$ \\
\hline TOTAL & 387 & $100,00 \%$ \\
\hline
\end{tabular}

Fuente: Elaboración propia a partir de los datos tomados de la encuesta aplicada a los comerciantes informales en las ciudades de Cúcuta, Ibagué y Villavicencio, julio de 2017

La encuesta realizada de forma directa a las personas le fue aplicada a 170 comerciantes informales que represento el 44,74\% del total encontrados en la fase de observación (387) v, de los cuales el $42,4 \%$ corresponden a mujeres y el 57,6\% a hombres, la mayoría de estas personas se encuentran vinculados a un sistema subsidiado de salud $(62,4 \%)$, mientras que un $24,1 \%$ corresponden al contributivo y un $13,5 \%$ no tienen ninguna de estas dos categorías.

Con relación al nivel educativo el promedio aritmético de años de escolaridad es 6 años y medio aproximadamente, mientas que la mayoría dice haber estudiado 5 años y del $25 \%$ que más han estudiado lo mínimo para estos son 10 años escolares.

Respecto a la tenencia de vivienda el 69,4\% dice vivir en alquiler y el 30,6\% tiene vivienda propia, por último la distribución respecto al estrato socioeconómico se encontró que la mayoría pertenece al estrato 1 , seguidos del estrato 2 .

Respecto a la descripción del negocio, en la ciudad de Villavicencio se encuentran 106 puestos en vía pública, 40 en Cúcuta y 132 en Ibagué; mientas que puestos ambulantes en Villavicencio 18, en Cúcuta 121 y en Ibagué 37.

El tiempo que los vendedores dedican a su negocio es alrededor de 9 horas al día y casi los siete días de la semana en las tres ciudades.

\subsubsection{Formas de financiación de los comerciantes informales}

Es de resaltar que en promedio para las tres ciudades, que el 78,5\% de los encuestados no tiene algún tipo de crédito con el sistema financiero; mientras que el 55.4\% ha tomado algún crédito con prestamistas informales para financiar su actividad. Este resultado demuestra que 
la mayoría no está vinculado al sistema financiero y recurren en última instancia a otras modalidades de financiación, como los prestamistas gota a gota, familiares y amigos, por la facilidad con que son otorgados estos recursos. Entre las principales razones que toman en cuenta para no recurrir al sistema bancario se destacan, la exigencia de garantías, los tramites tediosos, y porque no necesita este tipo de recursos.

El 55.4\% de los vendedores informales ha sido el promedio de las tres ciudades que ha tomado crédito con prestamistas infórmales para financiar la actividad comercial, siendo Villavicencio la ciudad que más participa en esta modalidad de préstamos, mientras que solo un $21.5 \%$ de estos vendedores tiene algún tipo de crédito con el sistema financiero. Este resultado demuestra el bajo nivel de bancarización para financiar su actividad y una proporción importante que toman créditos informales.

Tabla No. 6 Tipo de créditos utilizados por los comerciantes informales

\begin{tabular}{|c|c|c|c|c|}
\hline \multirow{3}{*}{ Ciudad } & \multirow{2}{*}{\multicolumn{2}{|c|}{$\begin{array}{c}\text { ¿Tiene algún tipo de crédito en } \\
\text { el sistema financiero? }\end{array}$}} & \multicolumn{2}{|c|}{$\begin{array}{c}\text { ¿Ha tomado algún crédito con los } \\
\text { prestamistas informales para } \\
\text { financiar la actividad? }\end{array}$} \\
\hline & & & \multicolumn{2}{|c|}{$\%$} \\
\hline & Sí & No & Sí & No \\
\hline Villavicencio & 19,3 & 80,7 & 57,3 & 42,7 \\
\hline Cúcuta & 22,4 & 77,6 & 52,4 & 47,6 \\
\hline Ibagué & 22,9 & 77,1 & 56,5 & 43,5 \\
\hline Promedio Total & 21.5 & 78.5 & 53.5 & 46.5 \\
\hline
\end{tabular}

Fuente: Elaboración propia a partir de los datos tomados de la encuesta aplicada a los comerciantes informales en las ciudades de Cúcuta, Ibagué y Villavicencio, julio de 2017

Tabla No. 7 Conoce los requisitos de los créditos del sistema financiero.

Conoce los requisitos que solicita el sistema financiero para acceder a un crédito

\begin{tabular}{ccccc}
\hline & Villavicencio & Cúcuta & Ibagué & Promedio \\
\hline $\mathrm{Si}$ & 44,7 & 41,2 & 63,5 & 49,8 \\
\hline $\mathrm{No}$ & 55,3 & 58,8 & 36,5 & 50,2 \\
\hline
\end{tabular}


Fuente: Elaboración propia a partir de los datos tomados de la encuesta aplicada a los comerciantes informales en las ciudades de Cúcuta, Ibagué y Villavicencio, julio de 2017

\subsubsection{Incidencia de los créditos informales en las actividades comerciales de los comerciantes informales}

La siguiente tabla muestra el número de comerciantes informales de las tres ciudades, que tuvieron alguna incidencia en el desarrollo de sus actividades, a través del acceso a créditos informales.

Tabla No. 8 Efecto de los créditos informales en las actividades comerciales de los vendedores ambulantes -2017 .

\begin{tabular}{|c|c|c|c|c|c|c|c|c|c|c|}
\hline \multirow[t]{2}{*}{ Característica } & \multicolumn{2}{|c|}{ Cúcuta } & \multicolumn{2}{|c|}{ Ibagué } & \multicolumn{2}{|c|}{ Villavicencio } & \multicolumn{2}{|c|}{ Total } & \multicolumn{2}{|c|}{$\begin{array}{c}\text { Participación } \\
\text { dentro del total }\end{array}$} \\
\hline & Si & No & Si & No & Si & No & Si & No & Si & No \\
\hline $\begin{array}{c}\text { ¿Amplio el tamaño } \\
\text { de su negocio? }\end{array}$ & 43 & 38 & 35 & 67 & 37 & 42 & 115 & 147 & $23,5 \%$ & $30,0 \%$ \\
\hline $\begin{array}{c}\text { Añadió productos } \\
\text { nuevos }\end{array}$ & 40 & 41 & 48 & 54 & 39 & 40 & 127 & 135 & $25,9 \%$ & $27,6 \%$ \\
\hline $\begin{array}{l}\text { ¿Contrato más } \\
\text { trabajadores? }\end{array}$ & 6 & 75 & 4 & 98 & 10 & 69 & 20 & 242 & $4,1 \%$ & $49,4 \%$ \\
\hline $\begin{array}{c}\text { ¿Redujo costos } \\
\text { comprando } \\
\text { insumos en } \\
\text { mayores } \\
\text { volúmenes o } \\
\text { precios al por } \\
\text { mayor? }\end{array}$ & 48 & 33 & 48 & 54 & 26 & 53 & 122 & 140 & $24,9 \%$ & $28,6 \%$ \\
\hline $\begin{array}{c}\text { ¿Empezó una } \\
\text { nueva actividad? }\end{array}$ & 12 & 69 & 11 & 91 & 11 & 68 & 34 & 228 & $6,9 \%$ & $46,5 \%$ \\
\hline $\begin{array}{c}\text { Vendió en nuevos } \\
\text { lugares }\end{array}$ & 8 & 73 & 9 & 93 & 12 & 67 & 29 & 233 & $5,9 \%$ & $47,6 \%$ \\
\hline total encuestados & 490 & & & & & & & & & \\
\hline
\end{tabular}

Fuente: Elaboración propia a partir de los datos tomados de la encuesta aplicada a los comerciantes informales en las ciudades de Cúcuta, Ibagué y Villavicencio, julio de 2017

Del $53,5 \%$ de comerciantes informales que solicito créditos informales solo $15,2 \%$ en promedio general se ha beneficiado de esta modalidad de préstamos, destacándose, el efecto principalmente en la adquisición de nuevos productos, la reducción de costos y la 
ampliación del negocio. Este resultado demuestra el bajo porcentaje que tiene la incidencia de los préstamos informales en las actividades de estas personas y la necesidad de orientar esquemas de financiación a través de la banca formal para que mejore la inclusión y los beneficios económicos.

El efecto de los créditos se ha reflejado principalmente en la adquisición de productos nuevos para mejorar el surtido del negocio entre ellos se destacan los siguientes: alimentos, accesorios para celular y para dama, ropa entre otros, también le han permitido reducir costos comprando insumos a mayores volúmenes y de alguna manera han ampliado el tamaño del negocio ubicando otro puesto en otro sector de estas ciudades. Como es de esperar, la contratación de trabajadores no es muy relevante dado que la mayoría son negocios familiares y sus miembros están involucrados en el desarrollo de este tipo de actividades.

También es muy bajo el porcentaje de comerciantes que gracias a estos créditos informales han decidido emprender una nueva actividad, la percepción es que muchos de ellos prefieren continuar en este tipo de negocios a pesar de las condiciones que deben afrontar y las opciones que algunas alcaldías locales como las de Ibagué y Villavicencio les ofrecen, para que ello se ubiquen en un lugar más organizado y menos expuesto, pero estas personas prefieren seguir vendiendo en condiciones de informalidad, dado que encuentran potenciales compradores en la vía pública, además de no pagar ningún tipo de impuesto, alquileres, y pago de nóminas.

\subsection{Resultados fase 3 aplicación modelo econométrico.}

Con base en los resultados del modelo estimado, las variables explicativas que incidieron de manera favorable en los beneficios de los comerciantes informales fueron: la posibilidad de vincularse al sistema financiero, y conocer los requisitos que exigen los bancos para acceder a productos y servicios. Las otras variables significativas son: tener créditos informales aunque estos inciden de manera negativa en los beneficios de los vendedores, es decir que por cada unidad de crédito informal, los beneficios disminuyen en 0,365 , este resultado demuestra que efectivamente, estos recursos son otorgados con altos costos así no estén representados en gastos financieros que exige la banca formal, afectando los ingresos, especialmente por las elevadas tasas de interés que deben asumir.

Contrario a lo esperado la variable frecuencia del surtido genero un efecto negativo en las ventas y por ende en los beneficios, lo cual indica que si aumenta el número de días en rotar los productos estos inciden en la acumulación de existencias disminuyendo los beneficios en ; sin embargo el número de dependientes es decir de personas familiares que viven del negocio inciden de manera positiva en las utilidades, lo cual demuestra que todos trabajan 
por un mismo beneficio, pero la seguridad social de sus miembros no es un factor determinante en los costos que asumen estos agentes económicos.

Las demás variables aunque no fueron significativas si generaron los resultados esperados, por ejemplo la financiación con recursos propios si incide de manera positiva en los beneficios, pues cuando estos comerciantes utilizan sus recursos en el sostenimiento del negocio no asumen ningún tipo de costos contables ni económicos.

\subsection{Resultados del Modelo}

A continuación se presentan los principales resultados del modelo de mínimos cuadrados ponderados donde la variable dependiente es el beneficio neto definido como la diferencia entre ingresos y gastos. Ver anexos A, B, C, D, E y F. (Ver tabla 9).

Tabla 9. Resultados del modelo.

\begin{tabular}{|c|c|c|}
\hline Variable & Descripción & Resultado esperado \\
\hline $\begin{array}{l}\log (\text { Beneficio }) \\
\text { Variable Independiente }\end{array}$ & & \\
\hline (Intercept) & $\begin{array}{l}12.501 \\
(0.265)\end{array}$ & $* * *$ \\
\hline $\begin{array}{l}\text { credito_siste } \\
\text { Independiente }\end{array}$ & $\begin{array}{c}0.457 \\
(0.162)\end{array}$ & $* *$ \\
\hline $\begin{array}{l}\text { conoce requisitos } \\
\text { variable Independiente }\end{array}$ & $\begin{array}{l}-0.569 \\
(0.165)\end{array}$ & $* * *$ \\
\hline $\begin{array}{l}\text { fincia_recursos_propios } \\
\text { variable Independiente }\end{array}$ & $\begin{array}{c}0.207 \\
(0.143)\end{array}$ & \\
\hline $\begin{array}{l}\text { Escolaridad } \\
\text { Variable Independiente }\end{array}$ & $\begin{array}{l}-0.015 \\
(0.016)\end{array}$ & \\
\hline $\begin{array}{l}\text { Vivienda propia } \\
\text { Variable Independiente }\end{array}$ & $\begin{array}{c}0.301 \\
(0.134)\end{array}$ & \\
\hline $\begin{array}{l}\text { TEA } \\
\text { Variable Independiente. }\end{array}$ & $\begin{array}{l}-0.012 \\
(0.012)\end{array}$ & \\
\hline
\end{tabular}




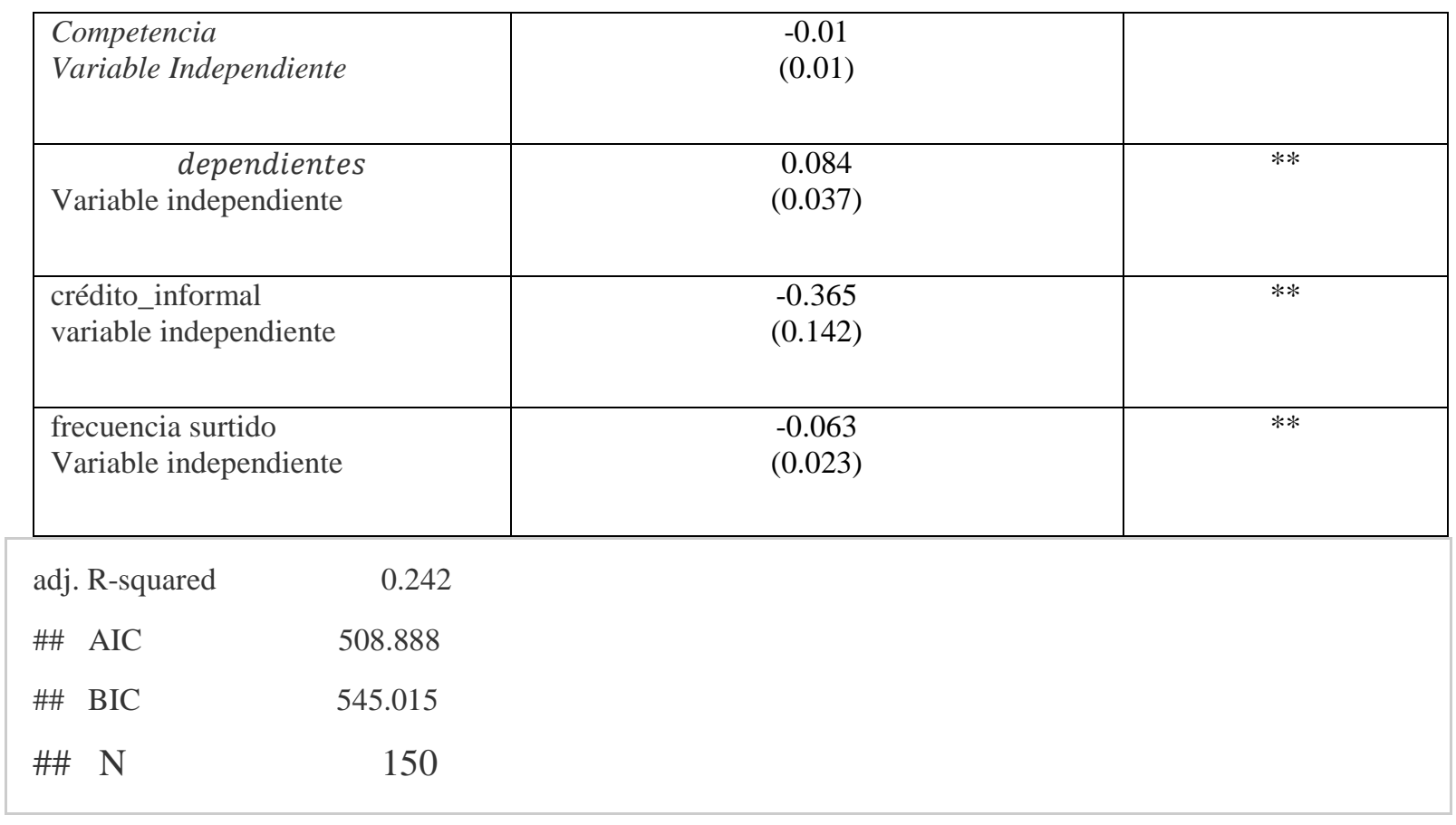

Fuente: Elaboración propia a partir de los datos tomados de la encuesta aplicada a los comerciantes informales en las ciudades de Cúcuta, Ibagué y Villavicencio, julio de 2017. Ver anexo $\mathrm{G}$

\section{Conclusiones.}

Una de las posibles causas del fenómeno que las personas accedan con más frecuencia a los créditos realizados por los prestamistas informales, puede ser que estos no exigen ningún tipo de garantía para su aprobación, pues esto fue lo argumentado por la mayoría de comerciantes, en las tres ciudades al preguntarles sobre si las personas o entidades les exigían algún tipo de garantías para la aprobación del crédito, el 90\% de Villavicencio dice que no, el Cúcuta el $60,49 \%$ dice no haber tenido esa exigencia y en Ibagué el $60 \%$.

La selección de las ciudades de Ibagué, Cúcuta y Villavicencio elegidas para desarrollar la investigación sobre la relación entre informalidad del comercio y los créditos informales, permitió evidenciar que existe una relación importante entre estas dos variables y demuestra la necesidad de estos agentes por utilizar este tipo de recursos para financiar su actividad económica, pero no se refleja en los beneficios de los comerciantes. Los créditos se otorgan con una tasa promedio del 20\%, y garantizan el capital de trabajo necesario para el sostenimiento del negocio y los beneficios económicos, pero no permiten ampliar el tamaño del negocio, simplemente garantizan su permanencia.

La inclusión financiera no se refleja en el impulso de las actividades informales, esta se presenta para apoyar créditos de consumo e hipotecarios, los comerciantes informales 
prefieren seguir recurriendo a los préstamos gota a gota u otras figuras crediticias informales a pesar de los riesgos que estos generan.

En términos generales podemos concluir que se presenta la misma tendencia en las ciudades seleccionadas, explicada en dos causalidades, primero los negocios informales que han tenido la posibilidad de acceder a créditos presentan mayores ganancias, pero existe un problema y es que estos créditos no son otorgados en su mayoría por entidades bancarias, sino por prestamistas informales, los cuales abusan de la condición y prestan a tasas de interés muy superiores, en este escenario es fundamental entender la inclusión financiera como una política de inserción productiva, entender las dinámicas de este tipo de financiamiento es fundamental, debido a que se deben asegurar cambios drásticos tanto en la oferta como en la demanda, se deben crear una nueva serie de servicios financieros destinados a este tipo de empresas, ya que éstas quedan marginadas de los servicios financieros formales.

El análisis anteriormente descrito pone en evidencia los efectos positivos de la posibilidad de endeudamiento y más si este es a tasas normales, es por eso que la inclusión financiera ya no solo se convierte en un mecanismo para la reducción de la pobreza, sino que tiene el potencial de generar cambios productivos, mediante las afectaciones que genera en términos del ahorro y el consumo, de igual manera permitirá generar mejorar en el aprovechamiento empresarial de esta población permitiéndoles responder a sus necesidades en cualquier parte del ciclo de vida o en cualquier etapa del proceso productivo.

Los vendedores informales son personas conscientes de su actividad ilegal, pero en la mayoría de los casos saben que es un negocio rentable no solamente por los resultados económicos, sino por tener la oportunidad de ser su propio jefe y trabajar de manera independiente, siendo un elemento motivante para continuar con esta actividad, pero es conveniente por parte de las autoridades locales, independiente del espacio público, convertir estas actividades en negocios formales, realizando inscripciones en censos y cámara de comercio, aprovechando la confianza legítima brindada por las alcaldías, quienes están en la obligación de apoyar a estas personas, con programas para que permitan mejorar sus actividades, y estructuras de sus negocios, así como impulsar sus emprendimientos.

Es un fenómeno de las ciudades más importantes del país la informalidad, por ello se ve en aumento la cantidad de vendedores informales que ocupan el espacio público de manera desorganizada, por tal motivo se hace necesario que las personas que desempeñan esta labor, desarrollen un proceso de autorregulación, con el fin de disminuir y prevenir las siguientes problemática como: invasión del espacio público, deterioro del ambiente donde se ubican los vendedores informales, presencia de delincuentes y vendedores en las zonas donde desarrollan su actividad comercial los vendedores informarles. Inadecuada manipulación de alimentos por parte de los vendedores informales, venta de elementos ilícitos y disposición inadecuada de las basuras, producto de las ventas. 


\section{Glosario}

Beneficios económicos. Se definen como la diferencia entre ingresos y costos (Varian, 2005)

Crédito informal, según la Asociación bancaria de Colombia este se define como aquellos prestamos efectuados por prestamistas informales como los gota a gota, casas de empeño grupos de autoayuda, familiares, amigos, estos recursos se obtienen inmediatamente pero son otorgados bajo condiciones de alto riesgo (Asobancaria, 2015).

Empleo informal. La decimoquinta conferencia Internacional de estadísticos del trabajo, define empleo informal como un conjunto de actividades dedicadas a la producción de bienes o prestación de servicios, con el fin de generar ingreso a las personas que participan en estas actividades con recursos de los hogares, pero no se constituyen en empresas con personería jurídica (DANE, 2009).

Mínimos cuadrados ponderados: es un caso especial del modelo de mínimos cuadrados generalizados y todas sus entradas están fuera de la diagonal $\Omega$. Este modelo se extiende a situaciones donde las observaciones no son independientes o hay presencia de heterocedasticidad. (Ramirez \& Benito, 2006, pág. 288)

Prestamos gota a gota, son una modalidad de créditos informales "otorgados por personas que operan en la informalidad, es una forma de delito configurado en la usura" (Rodriguez \& Obando, 2015).

Proporción de informalidad. Corresponde al cociente entre el total de población ocupada de manera informal y el número de personas que hacen parte de la población ocupada (DANE, 2018).

Régimen contributivo: constituye uno de los aspectos normativos que definen la vinculación de la población en Colombia al sistema general de seguridad social en salud, mediante el cual la contribución se efectúa de manera individual o familiar, según la ley 100 dicha contribución la efectúan las personas con capacidad de pago (Ministerio de Salud y Proteccion Social, 1993).

Régimen subsidiado. Fue diseñado para que las personas más pobres y vulnerables que no tienen capacidad de pago para que tengan acceso a la salud general subsidiado SGSSS, dicho régimen se financia con aportes fiscales de la Nación. (Ministerio de Salud y Proteccion Social, 1993).

Tasa Global de Participación TGP, según el Departamento Administrativo Nacional de Estadística DANE se define como: "la relación porcentual entre la población económicamente activa y la población en edad de trabajar. Es indicador refleja la presión de la población sobre el mercado laboral" (DANE, 2009). 
Vendedor ambulante. De acuerdo al Acuerdo 37 de 1932 el concejo de Bogotá considera como vendedor ambulante: "Todos aquellos individuos que venden mercancías, ya ofreciéndolas en las vías públicas, ya en los domicilios y locales particulares, ya en los salones de espectáculos, sea por medio de muestrarios, facturas u otros sistemas" (Concejo de Bogotá, 1932).

De acuerdo a la sentencia T-772/03 la Corte Constitucional de la Republica de Colombia , establece tres tipos de categorías de vendedores ambulantes: "los vendedores informales estacionarios quienes se instalan junto con sus implementos, bienes y mercancías de manera fija en un determinado segmento de espacio público; también están los vendedores informales semi estacionarios quienes no ocupan de manera permanente una parte del espacio público tomando como ejemplo los vendedores de alimentos y comidas rápidas y la última categoría los vendedores informales ambulantes quienes portan físicamente sobre su persona los bienes y las mercancías para las ventas" (corteconstitucional, 2003).

Financiación: Este proyecto fue financiado por la Universidad Santo Tomás de Bogotá Colombia con recursos del Fondo de Investigación FODEIN 2017. 


\section{Referencias bibliográficas}

Alcaldia de Villavicencio . (2017). Alcaldia de villavicencio . Obtenido de http://www.villavicencio.gov.co/MiMunicipio/Paginas/Presentacion.aspx

Aryeetey, E. (2008). From Informal Finance to Formal Finance in Sub-Saharan Africa: Lessons from Linkage Efforts. Paper Presented at the High-Level Seminar on African Finance for the 21st Century, University of Ghana, Institute of Statistical, Social and Economic Research, Tunicia.

Asobancaria. (21 de Agosto de 2015). http://www.asobancaria.com/sabermassermas/credito-informal/. Recuperado el 22 de Junio de 2018

Cámara de Comercio de Cúcuta. (2016). Boletín Económico Panorama Económico 2016 y proyecciones para el 2017. Cúcuta: Observatorio Económico.

Concejo de Bogotá. (1932). Regímen Legal de Bogotá D.C. Acuerdo 37 de 1932, Bogotá D.C. Recuperado el 19 de Junio de 2018

corteconstitucional. (2003). http://www.corteconstitucional.gov.co/relatoria/2003/t-77203.htm. Recuperado el 19 de junio de 2018, de http://www.corteconstitucional.gov.co.

DANE. (2009). METODOLOGIA INFORMALIDAD GRAN ENCUESTA INTEGRADA DE HOGARES - GEIH. Bogotá Colombia. Obtenido de https://www.dane.gov.co/files/investigaciones/boletines/ech/ech_informalidad/meto dologia_informalidad.pdf

DANE. (10 de Octubre de 2017). http://www.dane.gov.co/index.php/estadisticas-portema/salud/informalidad-y-seguridad-social/empleo-informal-y-seguridad-socialhistoricos. Recuperado el 20 de Nociembre de 2017

DANE. (2017). MEDICIÓN DE EMPLEO INFORMAL Y SEGURIDAD SOCIAL TRIMESTRE ABRIL - JUNIO DE 2017. Bogota Colombia: DANE. Obtenido de http://www.dane.gov.co/files/investigaciones/boletines/ech/ech_informalidad/bol_e ch_informalidad_abr17_jun17.pdf

DANE. (12 de Enero de 2018). https://www.dane.gov.co/files/investigaciones/boletines/ech/ech_informalidad/bol_e ch_informalidad_sep17_nov17.pdf. (DANE, Editor) Recuperado el 26 de 6 de 2018

Keynes, J. M. (2003). Teoría General de la Ocupación el interés y el dinero. México D.F.: Fondo de Cultura Económica. 
Ministerio de Salud y Proteccion Social. (1993). https://www.minsalud.gov.co/proteccionsocial/Regimencontributivo/Paginas/regim en-contributivo.aspx. (M. d. Social, Productor) Recuperado el 2018 de junio de 26

Racanello, K. (2013). Fuentes Informales de financiamiento. En Un acercamiento a la eficiencia del microfinanciamiento en Mexico (pág. 20). Mexico.

Ramirez, V. G., \& Benito, R. V. (Enero-junio de 2006). Colinealidad y Mínimos ciadrados ponderados. (U. C. Venezuela, Ed.) Revista venezolana de Analisis de Coyuntura, XII(1), 293-296.

Robinson, M. (2001). The microfinance Revolution. (W. Communications Development Incorporated, Ed.) Washington, D.C, USA.

Rodriguez, L. J., \& Obando, B. J. (2015). Impacto financiero causado por los cuentagotas en microempresarios de Villavicencio. Trabajo de grado para optar el título de Magister en Administración., Universidad Nacional de Colombia sede Manizales (UNILLANOS), Villacicencio. Recuperado el 22 de Junio de 2018

Romer, D. (2005). Macroeconomía Avanzada (Tercera Edición. ed.). (U. d. California, Ed.) USA: Mc Graw Hill.

Varian, H. (2005). Microeconomía Intermedia. Barcelona: Antoni Bosch. 


\section{ANEXO A}

Pruebas desarrollo modelo econométrico.

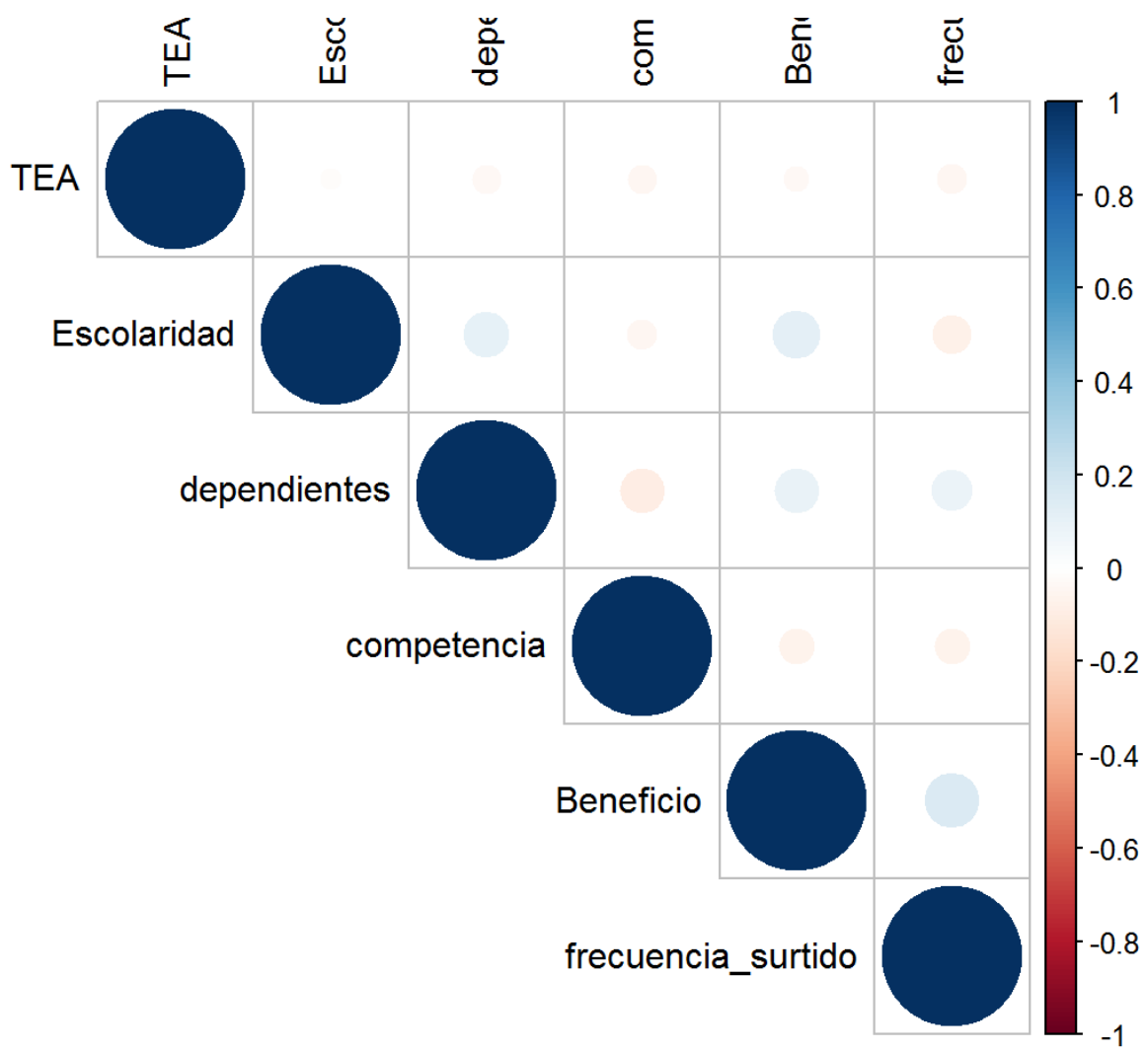

Fuente: Elaboración propia a partir de los datos tomados de la encuesta aplicada a los comerciantes informales en las ciudades de Cúcuta, Ibagué y Villavicencio, julio de 2017 


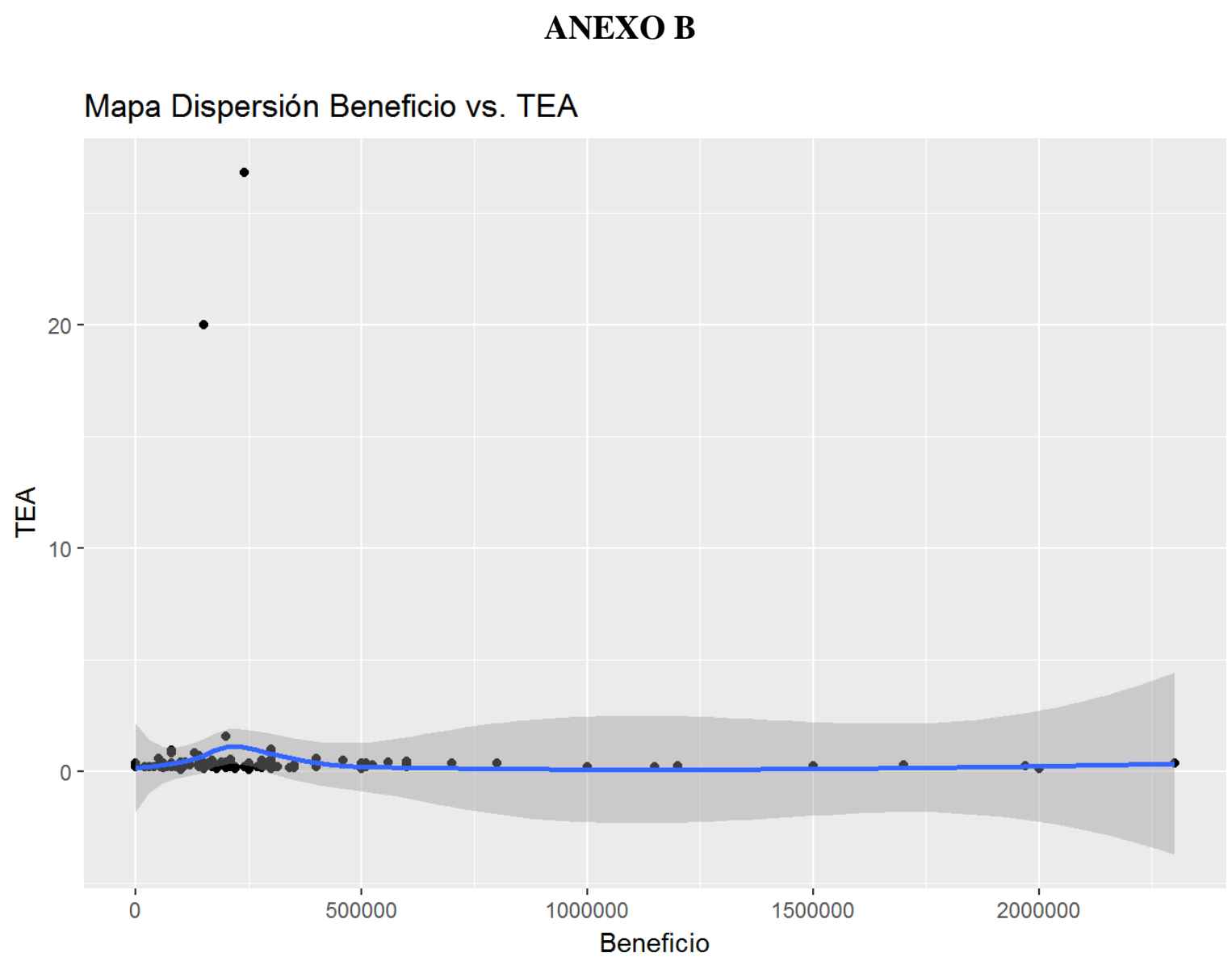

Fuente: Elaboración propia a partir de los datos tomados de la encuesta aplicada a los comerciantes informales en las ciudades de Cúcuta, Ibagué y Villavicencio, julio de 2017 


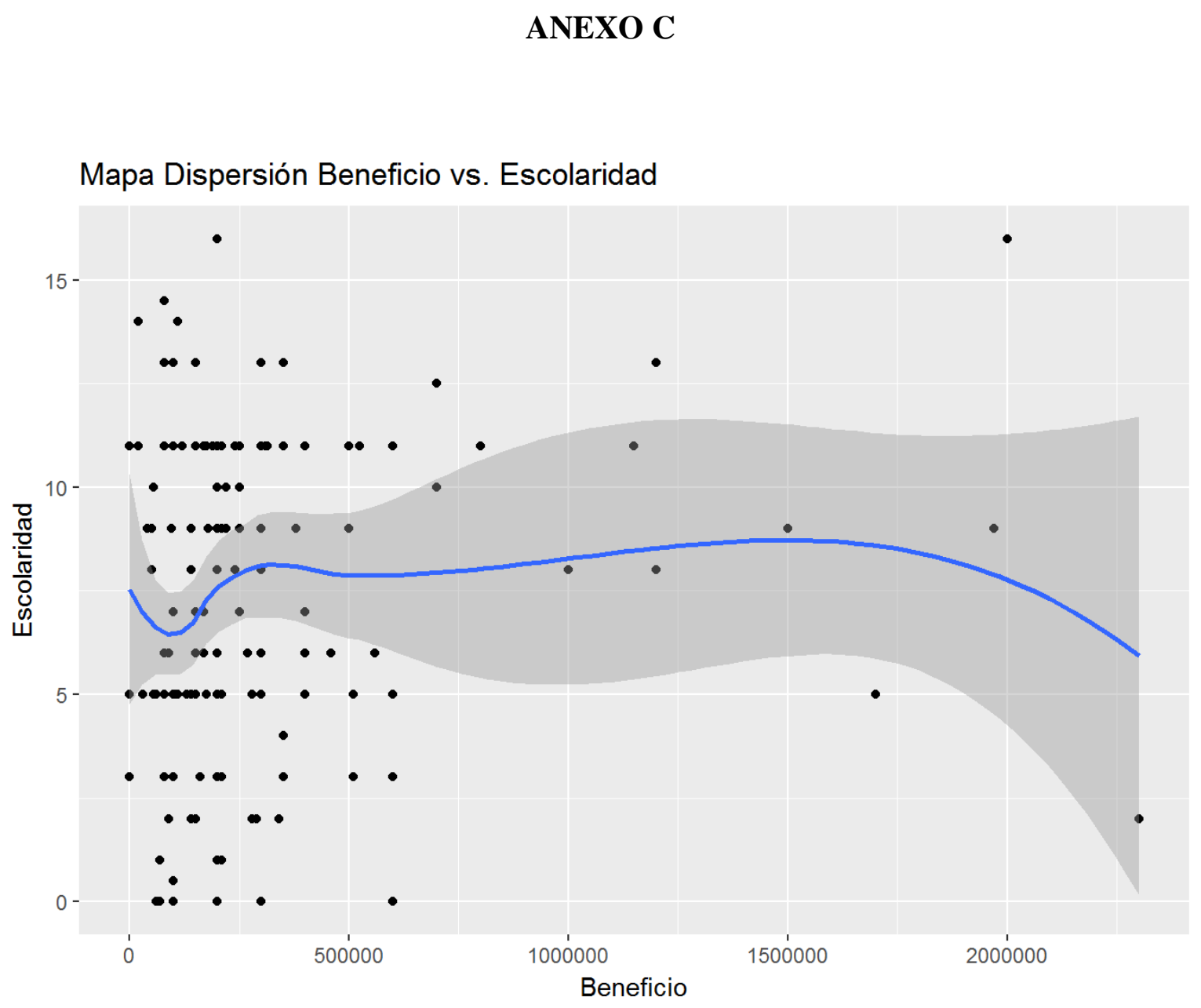

Fuente: Elaboración propia a partir de los datos tomados de la encuesta aplicada a los comerciantes informales en las ciudades de Cúcuta, Ibagué y Villavicencio, julio de 2017 


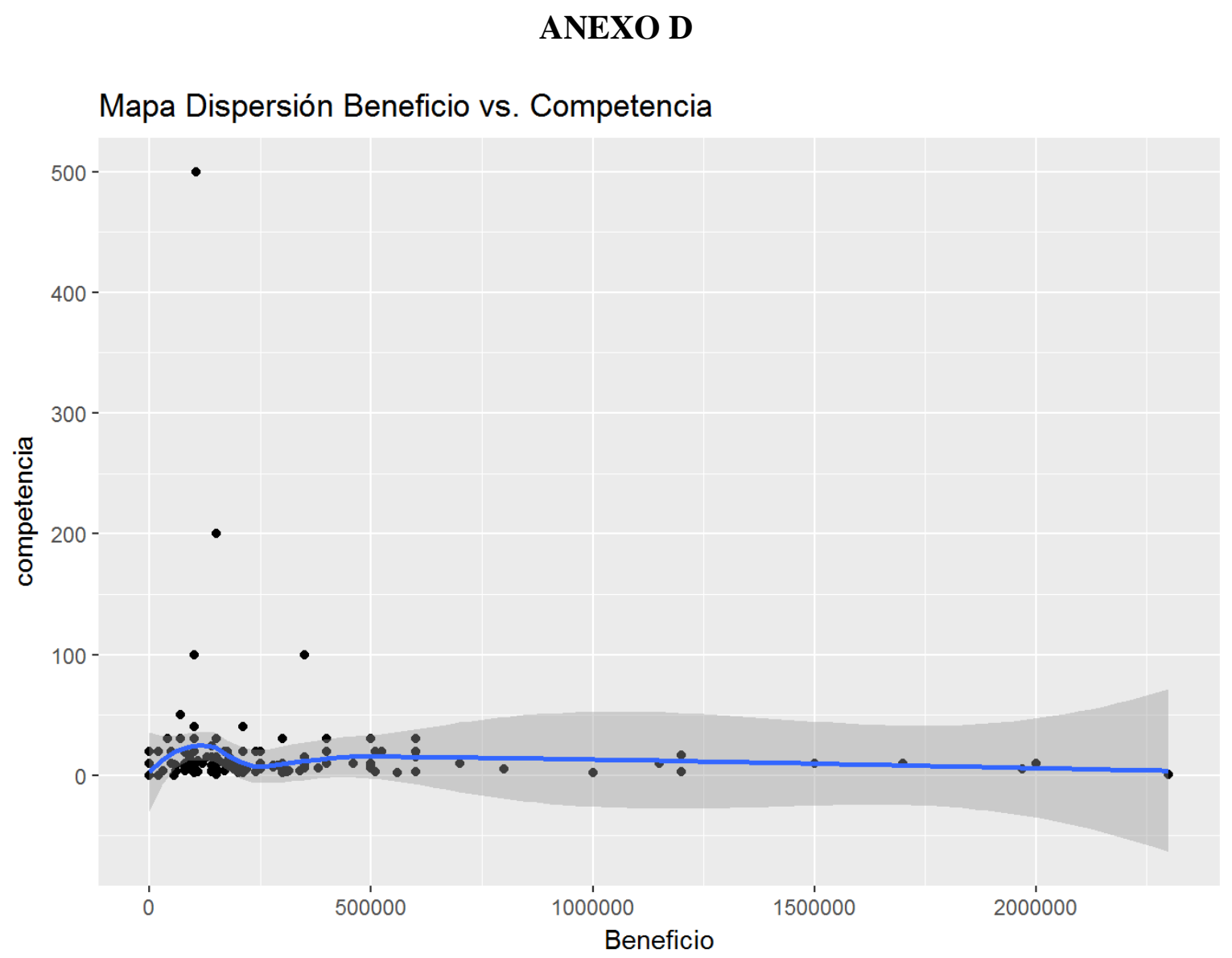

Fuente: Elaboración propia a partir de los datos tomados de la encuesta aplicada a los comerciantes informales en las ciudades de Cúcuta, Ibagué y Villavicencio, julio de 2017 


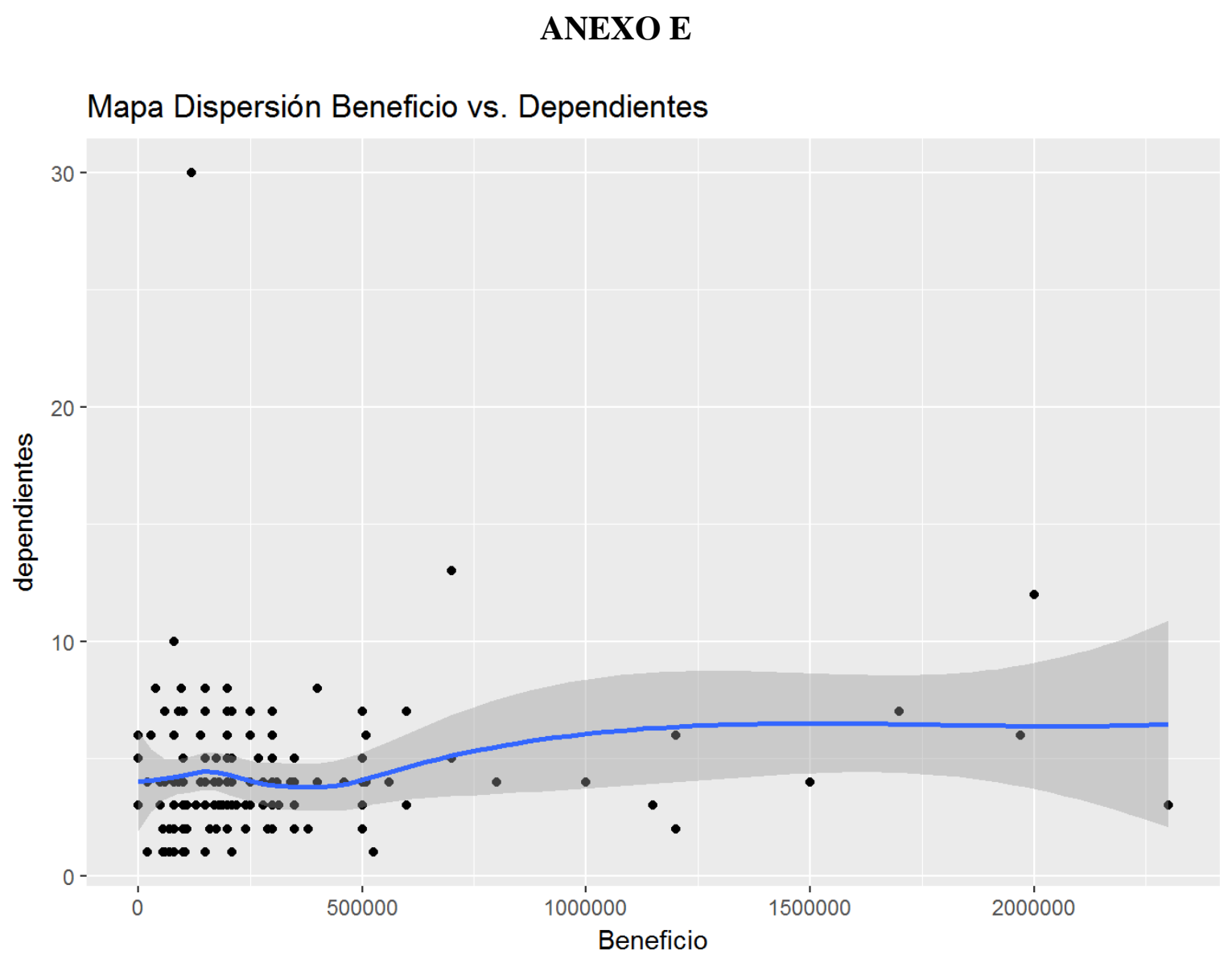

Fuente: Elaboración propia a partir de los datos tomados de la encuesta aplicada a los comerciantes informales en las ciudades de Cúcuta, Ibagué y Villavicencio, julio de 2017 


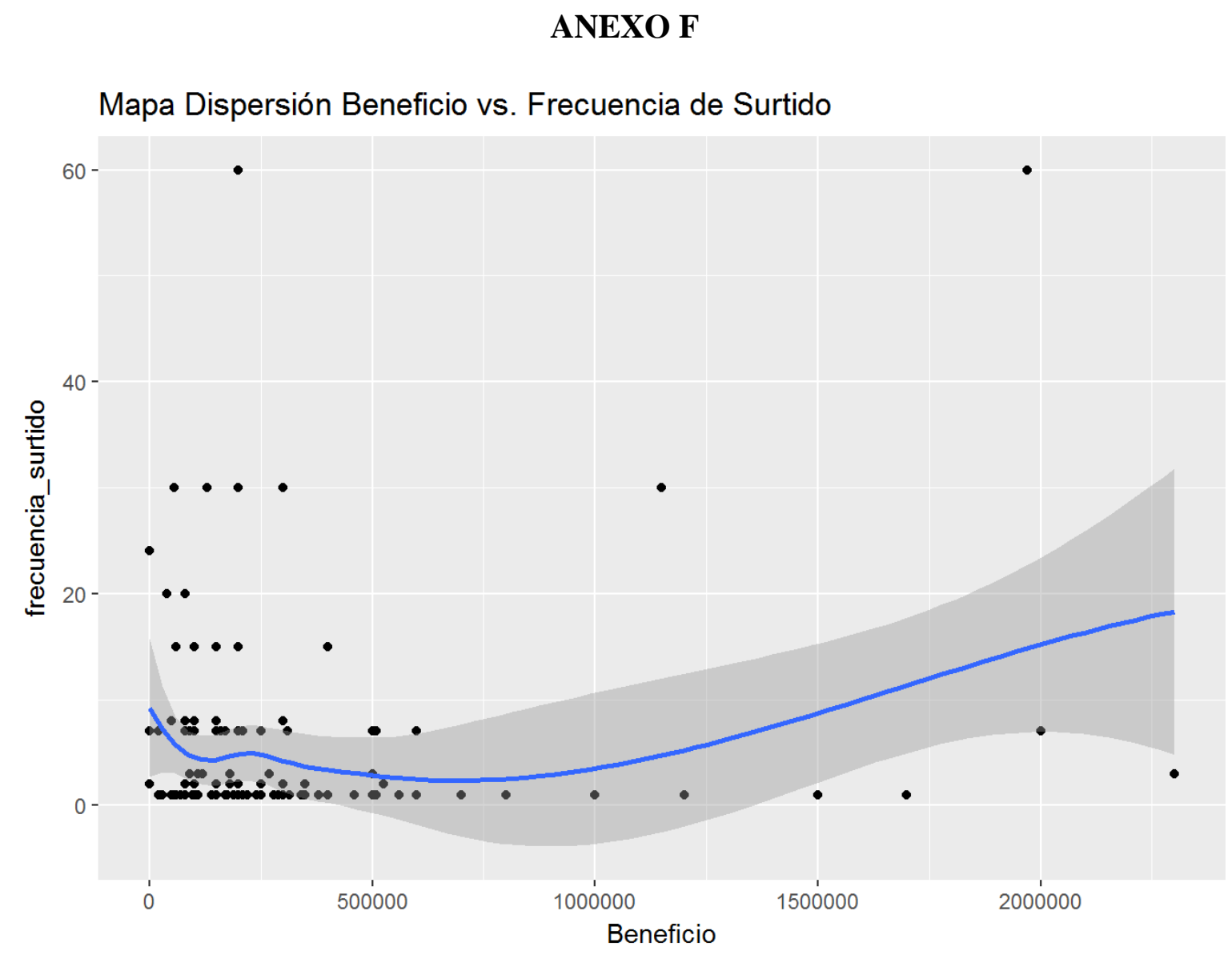

Fuente: Elaboración propia a partir de los datos tomados de la encuesta aplicada a los comerciantes informales en las ciudades de Cúcuta, Ibagué y Villavicencio, julio de 2017 


\section{ANEXO G}

\section{Mínimos cuadrados ponderados}

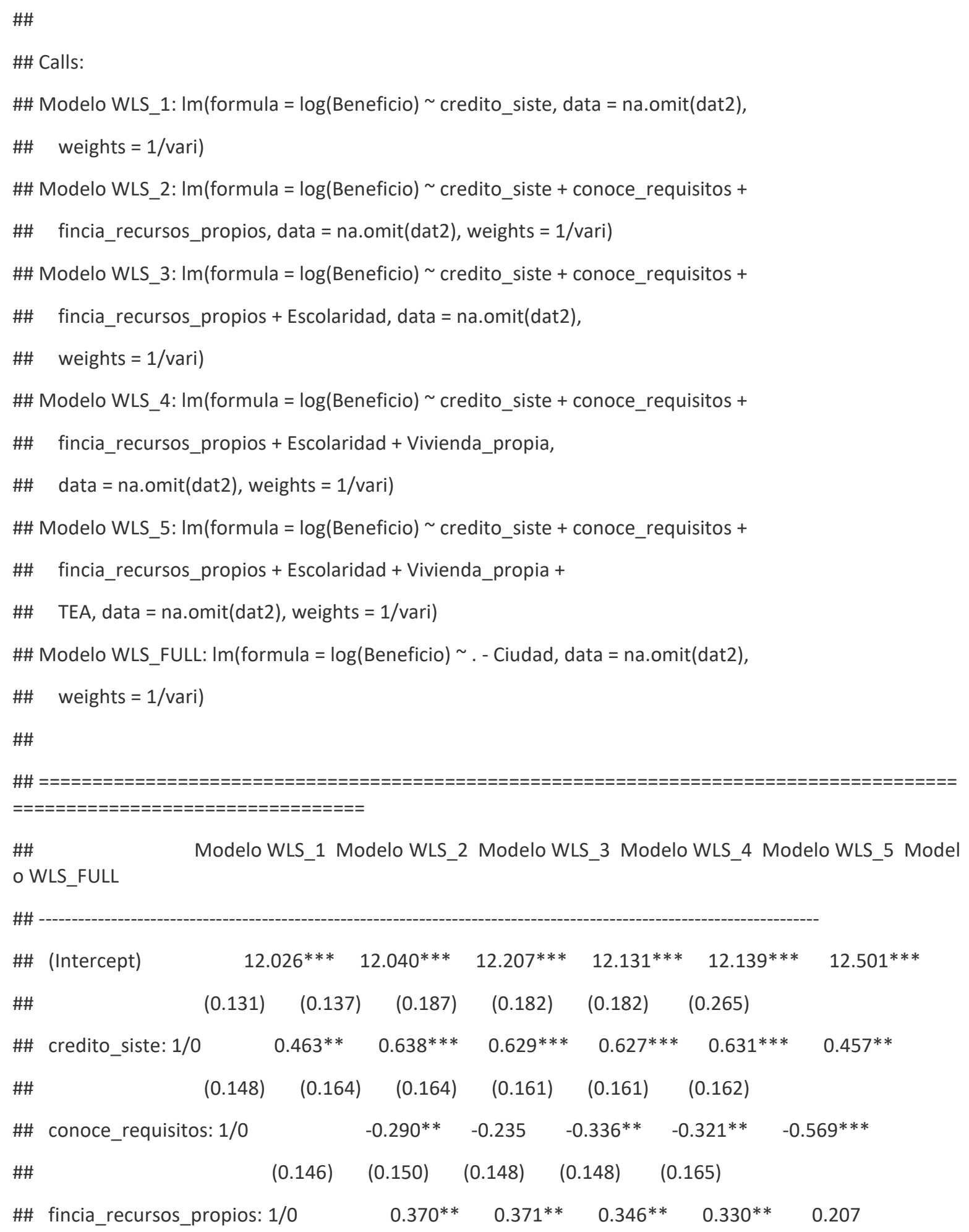




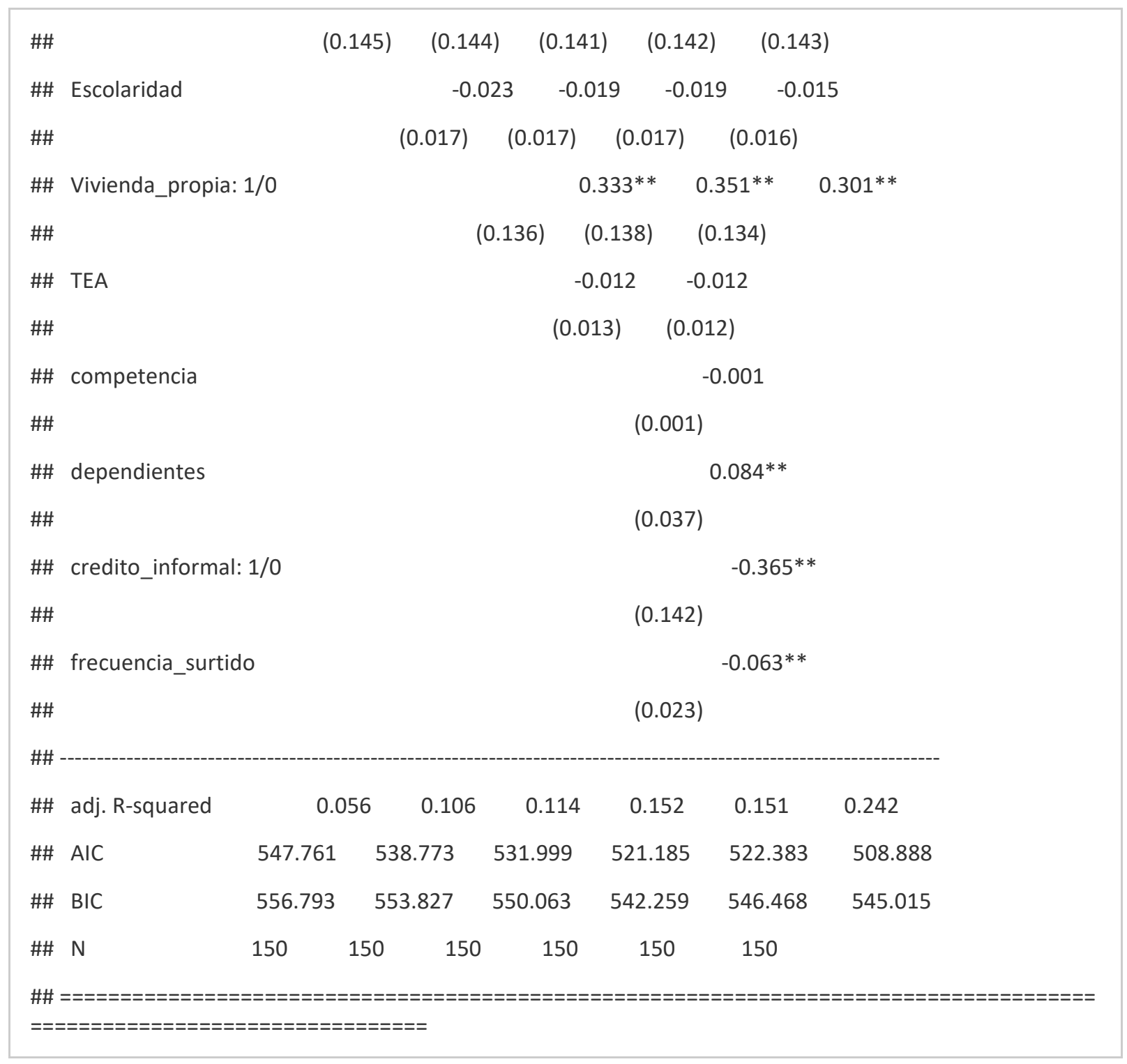

Fuente: Elaboración propia a partir de los datos tomados de la encuesta aplicada a los comerciantes informales en las ciudades de Cúcuta, Ibagué y Villavicencio, julio de 2017. 